\title{
O DESAFIO DE TRANSFORMAR OS CONFLITOS EM UMA IDEIA POSITIVA
}

\author{
THE CHALLENGE OF TURNING \\ CONFLICTS INTO A POSITIVE IDEA
}

\author{
Alinne Cardim Alves ${ }^{1}$ \\ Cassiane de Melo Fernandes ${ }^{2}$
}

Recebido em: 29/05/2017

Aprovado em: 14/08/2017

\section{RESUMO}

Atualmente, buscamos sempre uma maneira de lidar com as diferenças. Pensar no conflito somente no viés negativo é incentivar que as amargas disputas familiares aumentem, processos judiciais se eternizem e guerras se iniciem. E o saldo final é a perda de oportunidades em resolver os conflitos de forma satisfatória para todos os atores envolvidos. O mundo globalizado e democrático é responsável por uma indústria de conflitos que emergem à medida que as pessoas têm mais acesso às informações. Todavia, os conflitos são necessários, inevitáveis e úteis e geralmente geram novas ideias. Seria difícil pensar em corrigir uma situação injusta se o conflito não aparecesse. Por isso, a ideia não é eliminar o conflito e sim transformar o modo como lidamos com as diferenças, algo importante no mundo de hoje. O acesso à justiça possibilita aos cidadãos levarem suas demandas ao judiciário na tentativa de ter seus conflitos resolvidos, porém a justiça sem sempre

\footnotetext{
${ }^{1}$ Mestre em Direito Constitucionalpelo Centro de PósGraduação da Instituição Toledo de Ensino - ITE/Bauru. Especialista em Direito Constitucional pela Universitá Degli Studi di Pisa. Membro da Asociación Mundial de Justicia Constitucional, Membro Adjunto da Asociación Argentina de JusticiaConstitucional e Membro da Asociación Colombiana de Direito ProcessualConstitucional.Advogada e Professora.

${ }^{2}$ Mestre em Direito pela Faculdade de Direito de Ribeirão Preto/SP - UNAERP. Especialista em Direito Empresarial pela Faculdade Barretos (FB). Conciliadora do Poder Judiciário. Docente da Faculdade Barretos Membro da Asociación Mundial de Justicia Constitucional. MembroAdjunto da Asociación Argentina de Justicia Constitucional e Membro da Asociación Colombiana de Direito Processual Constitucional. Advogada.
} 
representa a voz das partes. O Estado, então, buscando corresponder aos anseios dos cidadãos na solução dos seus conflitos por meio das políticas públicas de tratamento adequado de conflitos de interesses, institui a Resolução 125/2010 que, entre outras atribuições, determina aos tribunais a criação dos Centros Judiciários de Solução de Conflitos e Cidadania (CEJUSC). Com isso, o juiz deixa de ser a única porta de acesso, surgindo um sistema de justiça multiportas. Nesta nova justiça, a justiça estatal clássica deixa der ser primazia nos litígios e passa a permitir a abertura para autocomposição. $\mathrm{O}$ acesso ao Direito vem sendo incentivado, de preferência sem contato ou passagem pelos Tribunais, buscando, assim, a tutela dos direitos de forma adequada, tempestiva e efetiva.

\section{PALAVRAS-CHAVE}

Autocomposição, Resolução 125/10, Conciliação, Mediação, Conflito.

\section{ABSTRACT}

Today, we are always looking for a way to deal with differences. To think of conflict only in the negative bias is to encourage bitter family disputes to escalate, lawsuits to perish, and wars to begin. And the final balance is the loss of opportunities to resolve conflicts in a way that is satisfactory to all actors involved. The globalized and democratic world is responsible for a conflict industry, which emerge as people have more access to information. However, conflicts are necessary, inevitable and useful, and usually generate new ideas. It would be difficult to think of correcting an unjust situation if the conflict did not arise. Therefore, the idea is not to eliminate conflict, but to transform the way we deal with difference, something important in today's world. Access to justice enables citizens to take their demands to the judiciary in an attempt to have their conflicts resolved, but justice does not always represent the voice of the parties. The State, seeking to respond to citizens' wishes to resolve their conflicts through public policies for the proper treatment of conflicts of interest, established Resolution 125/2010, which among other tasks, determines to the courts the creation Judicial Centers for Conflict Resolution and Citizenship (CEJUSC). With this, the judge ceases to be the only door, and a multi-court justice system emerges. In this new justice, the classic state justice, ceases to be primacy in litigation, allowing openness to self-composition. The access to the right, has been encouraged, of prefence without contact or passage through the Courts. Thus, we seek the protection of rights in an appropriate, timely and effective manner.

\section{KEYWORDS}

Self-composition; Resolution 125/10; Conciliation; Mediation; Conflict. 


\section{Introdução}

A Constituição Brasileira sedia o acesso a justiça no artigo $5^{\circ} \mathrm{XXXV}$ e com previsão no Novo Código de Processo Civil Brasileiro em seu artigo $3^{\circ}$, caput.

Esse "acesso a uma determinada justiça desenfreada" deve ser reanalisado. No mundo atual, globalizado, outros caminhos encontram-se abertos para equalizar os conflitos. O acesso à justiça, descrito na Constituição Brasileira de 1988, trouxe uma explosão de litígios cujas suas respostas deixam a desejar. Assim, criou-se um ambiente propício para a crise do judiciário aumentando a litigiosidade, sem que o Estado tenha condições para atendê-la.

Portanto, diversas pessoas acabam por não satisfazerem o seu direito e tão pouco solucionar seu litígio. A insatisfação pode ser tanto do autor como do réu ante uma sentença baseada nos fatos expostos nos autos, posto que as provas podem não terem sido produzidas adequadamente.

Porém, numa sessão de mediação ou em uma audiência de conciliação, um diálogo conduzido de forma correta, permite que sejam apresentados pelas partes outros fatos e acontecimentos que mudam o deslinde do encontro. Precisamos entender que o conflito sempre é maior do que o pedido realizado na petição inicial, assim, a abertura do diálogo incentiva as partes a exporem os motivos que estão impedindo que o conflito seja resolvido.

Uma sessão de mediação permite que se possa trabalhar com os sentimentos e, muitas vezes, aquele pedido expresso na petição inicial, perde o sentido, frente ao restabelecimento do diálogo entre as partes.

Incentivamos, assim, o interesse e afastamos os super poderes que as partes acreditam ter sobre o outro, objetivando o gerenciamento do conflito de forma adequada no entendimento de que este fenômeno surge naturalmente como produto interação interpessoal e que o mesmo não é tão ruim.

Assim, os conceitos estão em constante evolução e transformação, bem como como os conflitos que, de acordo com a teoria moderna do conflito, passou a ser visto pelo espiral positivo e não negativo.

Dessa forma, precisamos adequar a linguagem apresentada pela legislação brasileira e apresentar os métodos adequados de conflito e não meios alternativos dele. É preciso ter em mente que não são métodos alternativos de conflito, porque não posso pensar que pode ser um ou outro, trabalhar no plano do "tanto faz", é preciso entender que para cada caso concreto deve ser realizado 
um estudo individual para saber qual o método mais adequado para se chegar a um resultado positivo sobre aquele conflito.

Para isso, foram instalados meios de resolução e mediação dos conflitos a fim de desenvolver ações para alcançar o acesso à justiça de modo efetivo e célebre visto que este não conseguia atender a inúmeras demandas ajuizadas dos cidadãos que a procuravam.

Neste contexto, foram desenvolvidas, em âmbito federal, as políticas públicas de tratamento adequado de conflitos de interesses, que instituiu a Resolução 125/ 2010 que entre outras atribuições, consta a determinação aos tribunais de criar Centros Judiciários de Solução de Conflitos e Cidadania (CEJUSC).

A resolução do Conselho Nacional de Justiça trouxe a busca da transformação do judiciário, visando um judiciário mais humanista, uma vez que de nada adianta a implementação da resolução com inúmeros verbos impositivos como: deverão, criarão, farão, se não mudarmos a nossa concepção sobre a visão positiva do conflito e trazer mais humanidade às relações.

Desta forma, o maior desafio da Resolução do Conselho Nacional de Justiça é trazer a ideia de que o conflito deve ser visto de forma positiva e não de forma negativa, bem como respeitar a escolha dos interessados e garantir que ela seja feita em igualdade de condições. Por fim, deve se adequar aquele conflito ao meio de tratamento correto, ressaltando que não há superioridade da justiça estatal em relação aos meios de solução de controvérsias.

Assim, os meios adequados de solução de conflitos são uma oferta justa e tempestiva, que favorecem a desjudicialização dos conflitos a fim de evitar que as partes se tornem adversas e ao final que se produza um resultado de vencedor e perdedor. Ao contrário, o que se busca, é o binômio: ganha-ganha - que alcança o resultado pretendido por ambas as partes afastando a adversidade e abrindo espaço para o dialógo.

\section{Resolução 125/2010 do Conselho Nacional de Justiça.}

Criou-se uma verdadeira política pública judiciária que cuida dos processos, mas que também deve criar e incentivar os métodos adequados de conflitos, leia- se: mediação e conciliação.

A criação da resolução do Conselho Nacional de Justiça que trata da mediação e da conciliação é forma de política pública de tratamento adequado na 
solução de conflitos, visando à prevenção das demandas, implementando as atividades pré-processuais de conciliação e mediação. A criação da Resolução 125 do Conselho Nacional de Justiça veio para apoiar as práticas que alguns Tribunais e Comarcas já se utilizavam.

Os objetivos da resolução são bem delineados como:

a) disseminar a cultura da pacificação social e estimular a prestação de serviço auto-compositivo de qualidade (Art. $\left.2^{\circ}\right)$;

b) incentivar os tribunais a se organizarem e planejarem programas amplos de auto-composição (Art. $4^{\circ}$ );

c) reafirmar a função de agente apoiador da implantação de políticas públicas do Conselho Nacional de Justiça (Art. $3^{\circ}$ ).

Ao Conselho Nacional de Justiça compete atuar de forma administrativa e financeira no Poder Judiciário, zelar pelo cumprimento do artigo $5^{\circ}$ e 37 da Constituição Federal, pela eficiência operacional ao acesso à Justiça e pela ordem jurídica justa.

Conforme leciona Kazuo Watanabe (2017).

Problemática do acesso à Justiça não pode ser estudada nos acanhados limites dos órgãos judiciais já existentes. Não se trata apenas de possibilitar o acesso à Justiça enquanto instituição estatal, e sim de viabilizar o acesso à ordem jurídica justa. ${ }^{3}$

Desta forma, o Conselho Nacional da Justiça, tenta cumprir com suas atribuições, desenvolvendo as políticas públicas de tratamento adequado de conflitos de interesses, cujas ações têm o intuito de dar cumprimento aos preceitos da nossa Carta Magna, para tornar efetiva a eficiência operacional do Poder Judiciário aos seus jurisdicionados, garantindo o acesso à justiça de forma célere e justa, por meio da conciliação e mediação, de forma padronizada, sem ignorar as especificidades de cada esfera, Estadual, Federal e do Trabalho, e de cada região.

O artigo $1^{\circ}$ da Resolução instituiu a Política Judiciária Nacional de tratamento de conflitos de interesses, com o objetivo de assegurar a todos o direito à solução dos conflitos por meios adequados, deixando claro que incumbe ao Poder Judiciá-

\footnotetext{
${ }^{3}$ WATANABE, Kazuo apud MINGATI, Vinícius Secafen; RICCI, Milena Mara da Silva. Conceito de acesso à justiça: a efetividade do processo como garantia de acesso à uma ordem jurídica justa. Disponível em: <http:// eventos.uenp.edu.br/sid/publicacao/artigos/1.pdf>. Acesso em: 23 jan. 2017. p. 05.
} 
rio, além da solução adjudicada mediante sentença, oferecer outros mecanismos de soluções de controvérsias, em especial os chamados meios consensuais, como a mediação e a conciliação, bem assim prestar atendimento e orientação ao cidadão. ${ }^{4}$

O Conselho Nacional de Justiça tem envidado esforços para mudar a forma com que o Poder Judiciário se apresenta, uma vez que o Estado tem falhado na sua missão pacificadora em razão de fatores como, dentre outros, a sobrecarga dos tribunais, as elevadas despesas com os litígios e o excessivo formalismo processual.

O ideal é adotar o sistema multiportas proposto por Frank Sander, qeu compõe um Judiciário como um centro de solução de disputas, com distintos processos, baseado na premissa de que há vantagens e desvantagens de cada processo que devem ser consideradas em função das características especificas de cada conflito.

Assim, ao invés de existir apenas uma porta (o processo judicial), trata-se de um amplo sistema com diversas portas as quais forma um "centro de justiça" os quais as parte direcionam podem ser direcionadas ao processo adequado.

Art. $7^{\circ}$ Os tribunais deverão criar, no prazo de 30 dias, Núcleos Permanentes de Métodos Consensuais de Solução de Conflitos (Núcleos), coordenados por magistrados e compostos por magistrados da ativa ou aposentados e servidores, preferencialmente atuantes na área, com as seguintes atribuições, entre outras:

IV - Instalar Centros Judiciários de Solução de Conflitos e Cidadania que concentrarão a realização das sessões de conciliação e mediação que estejam a cargo de conciliadores e mediadores, dos órgãos por eles abrangidos. ${ }^{5}$

Para tanto, o Judiciário hoje tem que responder a seguinte indagação:

Como devo abordar essa questão para que os interesses que estão sendo pleiteados sejam realizados de modo mais eficiente, com maior satisfação do jurisdicionado e no menor prazo?

Neste contexto de se estimular o uso de práticas cooperativas em processo

\footnotetext{
${ }^{4}$ PINHO, Humberto Dalla Bernardina de; PAUGGARTTEN; Michele Pedrosa. Os desafios para a integração entre o sistema jurisdicional e a mediação a partir do Novo Código de Processo Civil: quais as perspectivas para a justiça brasileira? In: ALMEIDA, Diogo Assumpção Rezende; PANTOJA, Fernanda Medina; PELAJO Samantha (Coord.). A mediação no novo código de processo civil. 2. ed. Rio de Janeiro: Forense, 2016. p. 21.

${ }^{5}$ Ibid. 
de resolução de disputas, o acesso à justiça deve, sob o prisma da autocomposição, estimular, difundir e educar seu usuário para melhor resolver conflitos por meio de ações comunicativas.

O que se busca é uma transformação progressiva dos núcleos com mais centros e mais atuação com maior número de conciliadores e mediadores capacitados, alterando a natureza, qualidade e quantidade dos serviços judiciários.

Assim, a resolução 125 do Conselho Nacional de Justiça busca a transformação de uma cultura de litígios para uma cultura mais colaborativa e cooperativa, tentando afastar a figura paternalista e impositiva do jogo social.

Portanto, o Judiciário caminha para se tornar um prestador de serviço com produtos diferenciados, customizáveis e que garantam colocar as partes no centro do jogo jurídico, retornando os profissionais legais à posição de assistentes.

A pacificação social e a criação da paz sempre foram uma "velha" vontade do Estado Democrático de Direito, tanto que trouxe uma previsão no preâmbulo da Constituição Federal Brasileira do princípio da fraternidade, justiça e solidariedade, mas que ainda encontra muita resistência pelos seus fatores culturais, históricos e políticos.

O maior desafio talvez seja a implementação da política pública trazida pelo Conselho Nacional de Justiça em âmbito nacional, refletindo sua existência em âmbito internacional na via cooperativa, cuja maior batalha é fazer com que os conflitos sejam resolvidos de forma satisfatória e as pessoas envolvidas naquele caso, alcancem a pacificação social.

Tal alcance possibilita que o conflito não seja instaurado novamente e que outros conflitos não insurgam tão facilmente. Somente assim, a política pública, de alteração da estrutura do judiciário, poderá ser modificada, se não conseguirmos com que a nação seja mais humanista.

\section{Lei da Mediação n. $13.140 / 2015$}

A Lei da Mediação disciplinou o instituto que vinha sendo aplicado extrajudicialmente e judicialmente para garantir maior efetividade e segurança jurídica aos procedimentos de conciliação e mediação.

Neste sentido, afirma Walsir Edson Rodrigues Júnior (2006):

Desta forma, a finalidade da Lei da Mediação não será a autorização do uso dessa forma de resolução de disputas no Brasil, pois ela pode e já esta sendo em- 
pregada por várias instituições públicas e privadas como comprovadas neste estudo. O objetivo maior da lei será, portanto, a regulamentação da atividade da mediação e dos seus procedimentos. ${ }^{6}$

Conforme artigo $2^{\circ}$ e seus incisos, a mediação deve ser conduzida com imparcialidade do mediador, dando tratamento igual às partes, mediante manifestação oral, sendo requisito entre outros, a informalidade, para que seja compreensível, sem utilizar termos judiciais de difícil compreensão e respeitando a autonomia da vontade das partes, ou seja, somente haverá a participação na mediação, com a concordância das partes, primando pela boa-fé de todos envolvidos, de forma que a mediação seja conduzida para a expressão da justiça.

Neste sentido, para uniformizar e regrar os procedimentos dos profissionais, a resolução traz previsão dos artigos $9^{\circ}$ a $12^{\circ}$, dos requisitos necessários para mediador extrajudicial e judicial, bem como da remuneração que deverá ser fixada pelos tribunais e custeada pelas partes.

Conforme resolução, o mediador extrajudicial pode ser qualquer pessoa capaz, que tenha a confiança das partes, e que tenha capacitação específica para conduzir a mediação, independentemente de integrar qualquer tipo de conselho, entidade ou classe, ou que nele esteja inscrito.

Quanto ao mediador judicial, exige-se que tenha graduação por pelo menos dois anos em curso superior de instituição devidamente reconhecida e que seja capacitado em escola reconhecida pela Escola Nacional de Formação e Aperfeiçoamento de Magistrados (ENFAM) ou pelos tribunais, de acordo com o Conselho Nacional de Justiça em conjunto com o Ministério da Justiça.

A qualificação imposta aos candidatos a mediador traz qualidade aos trabalhos, como preleciona Maria Lúcia Pizzotti (2013).

Seguindo a ideia de qualificação impositiva desses profissionais, o Conselho Nacional de Justiça prudentemente se preocupou com a parte prática do trabalho em si, especificando que fará parte do aperfeiçoamento do profissional, além de um treinamento que pode ser feito inicialmente por dinâmicas, durante o curso realizado, deverá se dar por meio de estágio obrigatório, vez que ao exercitar os ensinamentos ministrados nos cursos, poderá adequá-los á realidade dos conflitos verdadeiros, quais sejam, envolvendo casos reais, com pragmatismo,

${ }^{6}$ RODRIGUES JÚNIOR, Walsir Edson. A prática da mediação eu acesso à justiça. Belo Horizonte: Del Rey, 2006. p. 209 
concretizando a teoria na prática, o que, repito, é vital para a boa qualidade dos trabalhos de conciliação.?

Cabe aos tribunais desenvolver ferramentas necessárias para cadastros efetuados pelos próprios mediadores, que podem escolher a jurisdição onde querem atuar e manter os dados atualizados dos candidatos autorizados e dos eventuais desligamentos, para consultas dos interessados e jurisdicionados.

Na mediação, as partes poderão ser assistidas por advogados ou defensor público sendo que, caso uma das partes esteja desacompanhada, deverá ser a mediação suspensa para realização em outra data, em que estejam todas assistidas.

Neste sentido, o acompanhamento de advogado ou defensor público na mediação, assistindo as partes, cumpre com o que prescreve o artigo 133 da Constituição Federal, e confirma a necessidade de mudança no paradigma cultural da litigiosidade, estimulando os advogados e defensores públicos a auxiliarem na busca de solução de conflitos, primando pela liberdade de escolha das partes.

A maior crítica à adoção do sistema multiportas são as dificuldades culturais dos operadores brasileiros, a necessidade de qualificar e preparar os profissionais para o exercício da mediação e da conciliação, a criação de centros para as sessões de mediação e audiências de conciliação, etc.

Fernanda Tartuce (2013) destaca a empatia, como ferramenta essencial a parte e seu advogado para se obter bons resultados na mediação:

Na literatura americana consta ainda a advertência de que o advogado deve estimular que seu cliente seja empático com a outra parte. Não há dúvidas de que tentar colocar-se no lugar do outro é conduta muito produtiva e valiosa para que a animosidade ceda espaço a posturas colaborativas. ${ }^{8}$

Ainda neste sentido, quanto à importância da presença e participação dos advogados na conciliação e mediação, destaca Marcela Rodrigues Souza Figueiredo (2016), que:

${ }^{7}$ PIZZOTTI, Maria Lúcia. Conciliação e mediação: da necessidade de adequada capacitação para obtenção de resultados efetivos. In: SILVA, João José Custódio da; AMORIM, José Roberto Neves (Coord.). A Nova Ordem das Soluções Alternativas de Conflitos e o Conselho Nacional de Justiça. São Paulo: Gazeta Jurídica, 2013. p. 236.

${ }^{8}$ TARTUCE, Fernanda. Advocacia e meios consensuais: novas visões, novos ganhos. In: SILVA, João José Custódio da; AMORIM, José Roberto Neves (Coord.). A Nova Ordem das Soluções Alternativas de Conflitos e o Conselho Nacional de Justiça. São Paulo: Gazeta Jurídica, 2013. p. 139. 
Essa atuação profissional ético-colaborativa dos assessores jurídicos, norteada pela primazia da construção de consenso, representa um novo significado sobre o sentido e a finalidade dessa atividade. A advocacia (pública ou privada) e a defensoria pública deixam de ser vistas como instrumentos de fomento ou perpetuação do litígio, tornando-se, essencialmente, potencializadoras da concretização dos interesses individuais, coletivos e sociais. ${ }^{9}$

A uniformização dos procedimentos da mediação, com a participação ativa de partes e advogados, possibilita a avaliação com maior segurança jurídica dos resultados para alcançar maior efetividade no cumprimento da lei, que se ampliou em 2015 com a promulgação do atual Código de Processo Civil, com capítulo próprio totalmente dedicado a Conciliação e Mediação.

\section{Código de Processo Civil de 2015 e a Mediação}

O procedimento da conciliação e mediação deixou de ser um instrumento baseado somente em experiências aplicadas individualmente por cada comarca, para ser um procedimento uniformizado e regulamentado pela Lei da Mediação e pelo Novo Código de Processo Civil, Lei 13.105/2015.

Corroborando, Diogo Assumpção Rezende de Almeida e Fernanda Medina Pantoja ( ano), destacam que

O Novo Código de Processo Civil enuncia, de forma inédita, dentre as suas normas fundamentais, a promoção da solução consensual dos conflitos pelo Estado, a ser estimulada por todos os operadores do Direito (art. $3^{\circ}, \S \S 2^{\circ}$ e $3^{\circ}$ ). A legislação reforça, assim, a devida importância da conciliação e da mediação, ao lado do processo judicial, como instrumento de pacificação social e de realização do direito de acesso à Justiça. ${ }^{10}$

Promulgado em 2015, o atual Código de Processo Civil estabelece que os métodos de solução consensual de conflitos devem ser promovidos pelo Esta-

${ }^{9}$ FIGUEIREDO, Marcela Rodrigues Souza. Considerações prático-teóricas da atuação dos assessores jurídicos na mediação. In: ALMEIDA, Diogo Assumpção Rezende; PANTOJA, Fernanda Medina; PELAJO, Samantha (Coord.). A mediação no Novo Código de Processo Civil. 2. ed. Rio de Janeiro: Forense, 2016. p. 298.

${ }^{10}$ ALMEIDA, Diogo Assumpção Rezende; PANTOJA, Fernanda Medina. Técnicas e procedimento de mediação no Novo Código de Processo Civil. In: ALMEIDA, Diogo Assumpção Rezende; PANTOJA, Fernanda Medina; PELAJO, Samantha (Coord.). A mediação no Novo Código de Processo Civil. 2. ed. Rio de Janeiro: Forense, 2016. p. $139-140$ 
do e serem estimulados em qualquer fase do curso do processo, em consonância com os artigos $1^{\circ}, 2^{\circ}$ e $3^{\circ}$ :

\begin{abstract}
Art. 1o processo civil será ordenado, disciplinado e interpretado conforme os valores e as normas fundamentais estabelecidos na Constituição da República Federativa do Brasil, observando-se as disposições deste Código.

$\S 2 \circ$ O Estado promoverá, sempre que possível, a solução consensual dos conflitos. $\S 3$ o conciliação, a mediação e outros métodos de solução consensual de conflitos deverão ser estimulados por juízes, advogados, defensores públicos e membros do Ministério Público, inclusive no curso do processo judicial. ${ }^{11}$
\end{abstract}

E estabeleceu no seu artigo 165 que os tribunais devem providenciar a criação dos Centros Judiciários de Solução de Conflitos - CEJUSC, que ficarão responsáveis pela realização das audiências de conciliação e mediação e autocomposição, não deixando de cumprir com o artigo $5^{\circ}$, inciso XXXV da Constituição Federal, de que "não excluirá da apreciação jurisdicional ameaça ou lesão a direito".$^{12}$

Regulando o Código de Processo Civil, "tanto a atividade judicial em sentido estrito, quanto os meios de solução consensual de controvérsias" ${ }^{\prime 13}$, oferecendo ao jurisdicionado um novo caminho para quem se sente ameaçado ou lesado em seu direito, para optar entre prosseguir com o processo confiando na aplicação da tutela jurisdicional, ou em escolher entre a conciliação ou mediação, pelo meio consensual que se entenda como mais adequado.

O objetivo maior de busca alcançar a paz social, neste sentido Petronio Calmon (2015).

Em resumo, diante do conflito, alguém que queira fazer valer os seus direitos em face de outrem possui duas alternativas: buscar a solução amigável (autocomposição) ou provocar a jurisdição (e o poder que lhe é inerente) a favor de sua

\footnotetext{
${ }^{11}$ BRASIL. Lei n. 13.105, de 16 de março de 2015. Código de Processo Civil. Disponível em: <http://www.planalto.gov.br/ccivil_03/_ato2015-2018/2015/lei//13105.htm>. Acesso em: 20 jan. 2017.

${ }^{12}$ BRASIL. Constituição da República Federativa do Brasil de 1988. Disponível em: <http://www.planalto.gov.br/ ccivil_03/constituicao/constituicaocompilado.htm>. Acesso em: 22 de jan. 2017.

${ }^{13}$ ALMEIDA, Diogo Assumpção Rezende; PANTOJA, Fernanda Medina. Técnicas e procedimento de mediação no Novo Código de Processo Civil. In: ALMEIDA, Diogo Assumpção Rezende; PANTOJA, Fernanda Medina PELAJO, Samantha (Coord.). A mediação no Novo Código de Processo Civil. 2. ed. Rio de Janeiro: Forense, 2016. p. 41 
pretensão. E ainda que tenha sido buscada a via jurisdicional, a qualquer momento os envolvidos podem se compor. Todos os meios, no entanto, possuem um escopo maior, a restauração da paz social. ${ }^{14}$

Cada tribunal teve a atribuição de compor e a organizar os centros, estabelecendo regras para atuação do Conciliador e Mediador.

Sendo que, no Capítulo V do referido código, encontramos o maior estímulo á autocomposição, sendo que uma das técnicas à autocomposição é a designação de uma audiência obrigatória de mediação ou conciliação, antes do oferecimento da resposta pelo réu, conforme previsto no artigo 334 do Código de Processo Civil.

Art. 334. Se a petição inicial preencher os requisitos essenciais e não for o caso de improcedência liminar do pedido, o juiz designará audiência de conciliação ou de mediação com antecedência mínima de 30 (trinta) dias, devendo ser citado o réu com pelo menos 20 (vinte) dias de antecedência. ${ }^{15}$

A conciliação e a mediação veem como obrigatoriedade quanto à ciência das partes da possibilidade de se utilizar deste mecanismo, porém sendo aplicado o princípio de autonomia da vontade das partes, podendo as partes se manifestarem pela concordância na participação da conciliação ou mediação, ou caso não tenham interesse poderão se manifestar com antecedência declarando expressamente pelo desinteresse, conforme parágrafos $4^{\circ}$ e $5^{\circ}$, do artigo 334 do atual Código de Processo Civil.

Caso o autor manifeste o desinteresse na mediação, mesmo que o requerido não se manifeste no prazo quanto a sua concordância ou não, o Juiz poderá neste caso, designar a sessão.

Contudo, a mediação, se for imposta, trará uma visão do Estado se impondo quanto à vontade das partes, deixando de ser a pacificação do conflito objetivo da mediação, o que não atende a proposta deste instituto.

Vale ressaltar que essa possibilidade de solução adequada de conflito vem resguardar e privilegiar a dignidade da pessoa humana, metadireito que deve

${ }^{14}$ CALMON, Petronio. Fundamentos da mediação e conciliação. 3. ed. São Paulo: Gazeta Jurídica, 2015. p. 20.

${ }^{15}$ BRASIL. Lei n. 13.105, de 16 de março de 2015. Código de Processo Civil. Disponível em: <http://www.planalto.gov.br/ccivil_03/_ato2015-2018/2015/lei//13105.htm>. Acesso em: 20 jan. 2017. 
ser efetivado sempre, posto que a autonomia de vontade das partes preserva a dignidade da pessoa humana quando o privilegia a ter direito de escolher entre ter seus conflitos resolvidos com a ajuda de um terceiro facilitador ou por meio da tutela jurisdicional.

E ainda podem optar quanto à aplicação da melhor técnica para solução do conflito e não apenas para por fim ao processo, conforme ressaltam Diogo Assumpção Rezende de Almeida e Fernanda Medina Pantoja (2016).

A mediação pode, com efeito, auxiliar na redução do número de processos. A experiência do já citado tribunal multiportas, no qual a mediação e outros mecanismos de solução de conflitos estão à disposição dos jurisdicionados, demonstra que podem ser desviados conflitos do curso da jurisdição para outras vias. Entretanto, a ideologia por trás desse modelo é a da adoção do mecanismo mais adequado para o enfrentamento de cada conflito, e, não a simples mudança de trajetória que sirva apenas à diminuição de litígios endereçados à jurisdição. Destarte, é apropriada a utilização da mediação desde que as suas técnicas se apresentem mais condizente a idiossincrasias do caso, dada a natureza do conflito, e não simplesmente se determinada corte ou juízo está assolado de trabalho. ${ }^{16}$

A mediação e conciliação não podem ser vistas como um meio de desafogar o judiciário, mas como opção para uma melhor forma de tratamento dos conflitos. $\mathrm{O}$ atual regramento processual estabelece que as ações de família devam ser conduzidas com todo esforço para solução consensual dos conflitos, com auxílio de profissionais de mediação e conciliação, podendo o andamento dos autos ser suspenso enquanto estiver em procedimento de mediação ou atendimento multidisciplinar, conforme artigo 694 do Código de Processo Civil:

Nas ações de família, todos os esforços serão empreendidos para a solução consensual da controvérsia, devendo o juiz dispor do auxílio de profissionais de outras áreas de conhecimento para a mediação e conciliação.

Parágrafo único. A requerimento das partes, o juiz pode determinar a suspensão do processo enquanto os litigantes se submetem a mediação extrajudicial ou a atendimento multidisciplinar. ${ }^{17}$

\footnotetext{
${ }^{16}$ ALMEIDA, Diogo Assumpção Rezende; PANTOJA, Fernanda Medina. Técnicas e procedimento de mediação no Novo Código de Processo Civil. In: ALMEIDA, Diogo Assumpção Rezende; PANTOJA, Fernanda Medina; PELAJO, Samantha (Coord.). A mediação no Novo Código de Processo Civil. 2. ed. Rio de Janeiro: Forense, 2016. p. 146.

17 BRASIL. Lei n. 13.105, de 16 de março de 2015. Código de Processo Civil. Disponível em: <http://www.planalto.gov.br/ccivil_03/_ato2015-2018/2015/lei/l13105.htm>. Acesso em: 20 jan. 2017.
} 
Demonstra que o legislador se preocupou em conduzir de forma adequada os conflitos familiares, instituto que merece uma grande atenção e cuidado no tratamento dos conflitos, com responsabilidade e delicadeza com as pessoas envolvidas, adultos e menores que necessitam não somente do empenho judicial, mas também de tratamento psicossocial e, neste contexto, a conciliação e mediação vêm como reforço a fim de restabelecer o diálogo entre as partes.

Assim, a mediação visa o restabelecimento da comunicação, com o reconhecimento dos seus sofrimentos, e principalmente com a possibilidade do mediador desenvolver a escuta entre as partes. Ao mediador cabe harmonizar os sentimentos dos conflitantes, visando que eles mesmos elaborem a melhor solução para o problema, enfrentando, uma vez que a solução alcançada de forma integrativa gera sentimento de satisfação e plenitude entre as partes, evitando que outras demandas sejam lançadas contra o outro.

Nas ações judicias individuais, os acordos não dependem de controle judicial, em regra e, na maior parte dos casos, as partes litigam sobre direitos disponíveis, não havendo necessidade de intervenção do poder judiciário para assegurar os seus direitos.

Importante ressaltar que a mediação e a conciliação também podem ocorrer no âmbito dos direitos coletivos, as quais permitem um espaço de negociação, como por exemplo, na Ação Civil Pública, todavia, nestes casos, primeiro há necessidade de tutela do objeto litigioso do processo, presente o interesse público, por se tratar de direitos de natureza coletiva; segundo, há necessidade da participação de grupos que serão afetados pela decisão e da participação dos colegitimados, pelo menos potencialmente, no âmbito do acordo a ser firmado; terceiro, há intervenção obrigatória do Ministério Público em todos os processos que tratam de direitos coletivos em sentido lato ${ }^{18}$.

Os bons trabalhos de voluntariados desenvolvidos não exime o Estado de reconhecer o direito à remuneração dos trabalhos do conciliador e mediador.

Neste sentido defende Valéria Ferioli Lagrasta Luchiari (2012),

Entretanto, o que se percebe é que essa remuneração é fundamental para assegurar a qualidade e a continuidade do serviço prestado junto ao Setor de Conci-

${ }^{18} \mathrm{NALINI}$, José Renato. Justiça Multiportas. Mediação, Conciliação, Arbitragem e outros meios de solução adequada de conflito. In: Hermes Zaneti Jr. E Trícia Navarro Xavier Cabral. Capítulo 1. Ė urgente construir alternativas á justiça. Salvador:Juspodivm, 2016.p.54. 
liação e Mediação, propiciando ao mediador motivação, inclusive, para aprimorar seus conhecimentos. ${ }^{19}$

Ressalta-se que os conciliadores e mediadores mereceram a atenção por parte do legislador, que promulgou a Lei n. 15.804/2015, que trata da remuneração dos trabalhos de conciliação e mediação. Contudo, a lei ainda não vem sendo cumprida, sendo a regulamentação quanto à forma do pagamento dos referidos honorários é de responsabilidade de cada Estado.

Assim, como novos fatos e acontecimentos vêm surgindo durante as gerações, não basta a legislação acompanhar as mudanças na sociedade, necessita também o Legislador cuidar para tornar efetivo seu cumprimento.

Desta forma, encontram-se inseridos no atual Código de Processo Civil, os procedimentos para tratamento adequado dos conflitos de interesses, seja no âmbito familiar ou cível, uma Lei específica para mediação e uma Lei para pagamentos dos conciliadores e mediadores, e para que se efetive o cumprimento das normas editadas, faz-se necessário também aliar a legislação o tratamento das partes, em um ambiente propício para tratar dos novos procedimentos propostos.

\section{Do Centro Judiciário de Solução de Conflitos e Cidadania}

A Resolução 125/10 instituída por meio da política pública de tratamento adequado de conflitos de interesses estabeleceu procedimentos para seu devido cumprimento. Para prosseguimento de efetivação dos meios consensuais estabelece a Resolução em seu artigo $1^{\circ}, \S$ único, a necessidade de que os cidadãos sejam orientados, através de atendimentos pelos Centros Judiciário de Solução de Conflitos e Cidadania (CEJUSC), órgãos judiciais em estruturas judiciárias centralizadas para incentivar a autocomposição, cujas unidades serão "preferencialmente, responsáveis pela realização ou gestão das sessões e audiências de conciliação e mediação que estejam a cargo de conciliadores e mediadores, bem como pelo atendimento e orientação ao cidadão" ${ }^{20}$

\footnotetext{
${ }^{19}$ LUCHIARI, Valéria Ferioli Lagrasta. Implantação efetiva dos métodos consensuais de solução de conflitos no judiciário. In: GRINIVER, Ada Pelegrini; WATANABE, Kazuo (Coord.). Mediação judicial: análise da realidade brasileira origem e evolução até a Resolução n. 125, do Conselho Nacional de Justiça. Rio de Janeiro: Forense, 2012. p. 101.

20 BRASIL. Conselho Nacional de Justiça. Resolução n. 125 de 29 de novembro de 2010. Dispõe sobre a Política Judiciária Nacional de tratamento adequado dos conflitos de interesses no âmbito do Poder Judiciário e dá outras providências. Disponível em: <http://www.cnj.jus.br/busca-atos-adm?documento=2579>. Acesso em: 21 abr. 2017. 
Utilizando para criação dos centros da experiência dos "Setores de Conciliação e Mediação do Estado de São Paulo e do Fórum de Múltiplas Portas ou Tribunal Multiportas (Multidoor Courthouse) do Direito norte-americano".$^{21}$

Sobre o Tribunal Multiportas, Valéria Ferioli Lagrasta Luchiari (2012) assim preleciona,

O Fórum de Múltiplas Portas ou Tribunal Multiportas constitui uma forma de organização judiciária, na qual o Poder Judiciário funciona como um centro de resolução de disputas, com vários e diversos procedimentos, cada qual com suas vantagens e desvantagens, que devem ser levadas em consideração no momento da escolha, em função das características específicas de cada conflito e das pessoas nele envolvidas. Em outras palavras, o sistema de uma única porta, que é a do processo judicial, é substituído por um sistema composto de variados tipos de procedimento, que integram um centro de resolução de disputas, organizado pelo Estado, composto de pessoas treinadas para receber as partes e direcioná-las ao procedimento mais adequado para o seu tipo de conflito. Nesse sentido, considerando que a orientação ao público é feita por um funcionário do Judiciário, ao magistrado cabe, além da função jurisdicional, que lhe é inerente, a fiscalização e o acompanhamento desse trabalho (função gerencial), a fim de assegurar a efetiva realização dos escopos do ordenamento jurídico e a correta atuação dos terceiros facilitadores, com a observância dos princípios constitucionais. ${ }^{22}$

A conciliação e mediação podem ser comparadas a portas autocompositivas por meio dos procedimentos conduzidos pelos Centros Judiciários de Solução de Conflitos e Cidadania (CEJUSC) instalados pelos tribunais de todos os Estados, para auxiliar na defesa dos direitos além da porta judicial.

A resolução estabelece aos tribunais de justiça por meio do Núcleo Permanente de Métodos Consensuais de Solução de Conflitos o dever de instalar os Centros ou CEJUSC - Centros Judiciário de Solução de Conflitos e Cidadania,

\footnotetext{
${ }^{21}$ LUCHIARI, Valéria Ferioli Lagrasta. Implantação efetiva dos métodos consensuais de solução de conflitos no judiciário. In: GRINIVER, Ada Pelegrini; WATANABE, Kazuo (Coord.). Mediação judicial: análise da realidade brasileira - origem e evolução até a resolução n. 125, do Conselho Nacional de Justiça. Rio de Janeiro: Forense, 2012. p. 92

${ }^{22}$ LUCHIARI, Valéria Ferioli Lagrasta. Implantação efetiva dos métodos consensuais de solução de conflitos no judiciário. In: GRINIVER, Ada Pelegrini; WATANABE, Kazuo (Coord.). Mediação judicial: análise da realidade brasileira - origem e evolução até a resolução n. 125, do Conselho Nacional de Justiça. Rio de Janeiro: Forense, 2012. p. 105.
} 
"nos locais onde existam 2 (dois) Juízos, Juizados ou Varas com competência para realizar audiência" ${ }^{23}$, enquanto que nos Tribunais Regionais Federais e Tribunais de Justiça "é facultativa a implantação de Centros onde exista um Juízo, Juizado, Vara ou Subseção desde que atendidos por centro regional ou itinerante, nos termos do parágrafo anterior" ${ }^{24}$

Neste contexto seguem os artigos 24 da Lei da Mediação e 165 do atual Código de Processo Civil determina a criação dos centros judiciários de solução de conflitos e cidadania (CEJUSC) que serão responsáveis pela realização de sessões e audiências de conciliação e mediação, pré-processuais e processuais, e pelo desenvolvimento de programas destinados a auxiliar, orientar e estimular a autocomposição. ${ }^{25}$

A cada tribunal cabe a atribuição de compor e organizar os centros, conforme previsão do Conselho Nacional de Justiça, de que deverão os centros ser compostos pelo setor de solução de conflitos pré - processual, setor de solução de conflitos processual e setor de cidadania. Neste sentido, quanto à estrutura do CEJUSC pondera João José Custódio da Silveira,

O que se espera dos órgãos diretivos é a implantação de centros modelares, com estrutura física e funcional adequada, capitaneados por um juiz com dedicação gerencial exclusiva, para que os índices de solução atingidos demonstrem a viabilidade do investimento - em muito inferior à criação de novas varas judiciais. ${ }^{26}$

A possibilidade do CEJUSC de estabelecer parcerias com outros órgãos de atendimento à população em cumprimento ao setor de cidadania, além de incluir no espaço estrutural, salas de audiências, ambiente ao Ministério Público, Defensor Público, procuradores, advogados, conciliadores e mediadores, requer a necessidade de se estruturar o ambiente e a devida capacitação dos

\footnotetext{
${ }^{23}$ BRASIL. Conselho Nacional de Justiça. Resolução n. 125 de 29 de novembro de 2010. Dispõe sobre a Política Judiciária Nacional de tratamento adequado dos conflitos de interesses no âmbito do Poder Judiciário e dá outras providências. Disponível em: <http://www.cnj.jus.br/busca-atos-adm?documento=2579>. Acesso em: 21 abr. 2017.

24 Ibid.

${ }^{25} \mathrm{Ibid}$

${ }^{26}$ SILVEIRA, João José Custódio da. Desafios à Nova Ordem de Soluções Diferenciadas para Acesso à Justiça In: SILVEIRA, João José Custódio da; AMORIM, José Roberto Neves (Coord.). A Nova Ordem das Soluções Alternativas de Conflitos e o Conselho Nacional de Justiça. Brasília: Gazeta Jurídica, 2013. p. 172.
} 
servidores para atendimento adequado à população.

A conciliação e mediação deixaram de ser um meio alternativo de solução de controvérsias, sendo reconhecido como meio adequado a ser oferecido antes de ajuizar as ações, nos termos do art. 334 do Novo Código de Processo Civil combinado com o art. 27 da Lei de Mediação, com o objetivo de se evitar uma solução adjudicada que poderá extinguir e arquivar um processo, mas pode não por fim ao conflito. Quanto à judicialização e ao incentivo à conciliação e à mediação, José Renato Nalini (2013) enfatiza,

A judicialização (grifo do autor) de todos os conflitos amarra a sociedade, mantém-na calada, sob a blindagem formalística do processo. Inibe a criatividade, sepulta a solidariedade, torna fraternidade (grifo do autor) uma palavra destinada à arqueologia semântica. Ao contrário: estimular as alternativas de resolução das controvérsias treina o ser humano para a maturidade. Faz com ele passe a desenvolver uma discernimento racional (grifo do autor) e não apenas atuar com o insuficiente discernimento instintivo (grifo do autor). Torna o direito um compromisso diuturno, vital para o convívio, não um conglomerado de regras destinadas a conhecimento apenas para iniciados. A justiça é virtude que pode e deve ser praticada por todos os humanos, não é um terreno minado de dificuldades, óbices, empecilhos e armadilhas, quais as hoje encontradas naquela arena de astúcias ou quintal de espertezas (grifo do autor) que é a instrução judicial. ${ }^{27}$

O incentivo pode ser visto como forma de lei, que prevê nos artigos 319 a 320 do Código de Processo Civil, de que as partes devem se manifestar expressamente quanto ao interesse ou não pela conciliação ou mediação, que caso haja omissão, terá a parte a oportunidade de regularizar dentro do prazo, e somente se decorrido o prazo sem manifestação ocorrerá o indeferimento da inicial.

O legislador chama a atenção para a oportunidade da solução consensual, e também incentiva a participação quando oferece a isenção de custas, prevista no artigo 29 da Lei da Mediação: “ [...] solucionado o conflito pela mediação antes da citação do réu, não serão devidas custas judiciais finais". ${ }^{28}$

${ }^{27}$ NALINI, José Renato. Implicações éticas nas alternativas de resolução de conflito. In: SILVEIRA, João José Custódio da; AMORIM, José Roberto Neves (Coord.). A Nova Ordem das Soluções Alternativas de Conflitos e o Conselho Nacional de Justiça. Brasília: Gazeta Jurídica, 2013. p. 212.

${ }^{28}$ BRASIL. Lei n. 13.140, de 26 de junho de 2015. Dispõe sobre a mediação entre particulares como meio de solução de controvérsias e sobre a autocomposição de conflitos no âmbito da administração pública; altera a Lei n. 9.469, de 10 de julho de 1997, e o Decreto n. 70.235 , de 6 de março de 1972 ; e revoga o $\S 2^{\circ}$ do art. $6^{\circ}$ da Lei n. 9.469, de 10 de julho de 1997. Disponível em: <http://www.planalto.gov.br/ccivil_03/_ato2015-2018/2015/ Lei/L13140.htm>. Acesso em: 02 maio 2017. 
A obrigatoriedade da manifestação sobre o interesse ou não pela conciliação, e da aplicabilidade de multa ante a ausência não justificada em audiência prevista no parágrafo $8^{\circ}$ do artigo 334 do CPC, não impõe a via consensual, posto que o legislador oferece as partes a oportunidade de se manifestarem até dez dias antes da audiência, deixando aqui implícito o respeito à voluntariedade.

Neste sentido, ressalta Humberto Dalla,

Por outro lado, não concordamos com a ideia de uma mediação ou conciliação obrigatória. É de essência desses procedimentos a voluntariedade. Essa característica não pode ser jamais ser comprometida, mesmo que sob o argumento de que se trata de uma forma de educar o povo e implementar uma nova forma de política pública. ${ }^{29}$

A obrigatoriedade traria a decisão adjudicada, o que não se pretende com a política judiciária de tratamento adequado de conflitos, que para isso prevê ferramentas para incentivar e não obrigar a aplicação dos métodos consensuais

Desde a conciliação aplicada no judiciário nacional ao longo de décadas até o movimento para implantação das políticas públicas de tratamento adequado de conflitos de interesses, o judiciário nacional tem sido foco de legisladores para oferecer aos cidadãos um acesso à justiça de maneira célere e eficaz, cuja metodologia para resolução dos processos tem sido modificada ao longo destes últimos anos, para a solução de conflitos de forma adequada.

O movimento se estendeu e teve com a política judiciária nacional instituída através da Resolução 125/2010 um avanço na legislação com a promulgação da Lei da Mediação n. 13.140/2015 e com capítulo próprio no atual Código de Processo Civil, além de estabelecer que a cada estado caberia a regulamentação da remuneração dos conciliadores e mediadores, cuja determinação no estado de São Paulo foi cumprida através da Lei n. 15.804/2015.

\section{Conclusão}

Vivemos em um cenário constitucional de ampliação aos direitos e garantias fundamentais, em que e destacam o acesso à justiça e à inafastabilidade do Judiciário, que são catalizadoras do crescimento das ações judiciais.

${ }^{29}$ DALLA, Humberto. Prefácio. In: SPENGLER, Fabiana Marion; BEDIN, Gilmar Antônio (Org.). Acesso à justiça, direitos humanos \& mediação. Curitiba: Multideia, 2013. p. 12. 
É inegável que o Poder Judiciário perdeu o controle da situação, sendo necessário implementar medidas para transformar esta situação.

Neste cenário, em 2010, o Conselho Nacional de Justiça editou a resolução 125 que dispõe sobre a política judiciária nacional de tratamento adequado dos conflitos de interesses, apresentando sua diretrizes básicas para transformar o judiciário em um ambiente mais humanizado, impondo metas aos Tribunais na criação dos Centros Judiciários de Solução de Conflitos e Cidadania (CEJUSC).

Na esteira dessa e de outras iniciativas, dois importantes instrumentos legais surgem para mudar esse cenário, beneficiando toda a sociedade e fazendo tribunais, empresas e cidadãos se adaptarem a uma nova cultura jurídica.

O novo Código de Processo Civil, em vigor a partir do ano de 2016, contempla a mediação ao lado da conciliação e da arbitragem, como meios adequados de solução de conflitos, determinando que profissionais do direito, de juízes a advogados, defensores a membros do Ministério Público, estimulem esses mecanismos.

Por sua vez, a Lei $n^{\circ}$ 13.140/15, conhecida como lei da mediação, não apenas regulamenta o uso dessa forma de solução de conflitos, mas o torna obrigatório em alguns casos, antes de iniciar um processo adversarial.

Assim, estes novos instrumentos, têm como desafio fazer com as pessoas entendam que o conflito, deve ser visto de forma positiva e não negativa.

Portanto, quando encaramos o conflito de forma positiva, temos a aproximação dos conflitantes, o amadurecimento e autoconhecimento das partes.

O maior ganho de se valer dos meios adequados de solução de conflitos e que as partes muitas vezes ganham sentimentos que as sentenças não conseguem atingir é o sentimento de que o conflito acabou de uma forma justa.

\section{REFERÊNCIAS}

ALMEIDA, Diogo Assumpção Rezende; PANTOJA, Fernanda Medina. Técnicas e procedimento de mediação no Novo Código de Processo Civil. In: ALMEIDA, Diogo Assumpção Rezende; PANTOJA, Fernanda Medina; PELAJO, Samantha (Coord.). A mediação no Novo Código de Processo Civil. 2. ed. Rio de Janeiro: Forense, 2016. 
CALMON, Petronio. Fundamentos da mediação e conciliação. 3. ed. São Paulo: Gazeta Jurídica, 2015.

DALLA, Humberto. Prefácio. In: SPENGLER, Fabiana Marion; BEDIN, Gilmar Antônio (Org.). Acesso à justiça, direitos humanos \& mediação. Curitiba: Multideia, 2013.

FIGUEIREDO, Marcela Rodrigues Souza. Considerações prático-teóricas da atuação dos assessores jurídicos na mediação. In: ALMEIDA, Diogo Assumpção Rezende; PANTOJA, Fernanda Medina; PELAJO, Samantha (Coord.). A mediação no Novo Código de Processo Civil. 2. ed. Rio de Janeiro: Forense, 2016.

TARTUCE, Fernanda. Advocacia e meios consensuais: novas visões, novos ganhos. In: SILVA, João José Custódio da; AMORIM, José Roberto Neves (Coord.). A Nova Ordem das Soluções Alternativas de Conflitos e o Conselho Nacional de Justiça. São Paulo: Gazeta Jurídica, 2013.

LUCHIARI, Valéria Ferioli Lagrasta. Implantação efetiva dos métodos consensuais de solução de conflitos no judiciário. In: GRINIVER, Ada Pelegrini; WATANABE, Kazuo (Coord.). Mediação judicial: análise da realidade brasileira origem e evolução até a Resolução n. 125, do Conselho Nacional de Justiça. Rio de Janeiro: Forense, 2012.

NALINI, José Renato. Justiça Multiportas. Mediação, Conciliação, Arbitragem e outros meios de solução adequada de conflito. In: Hermes Zaneti Jr. E Trícia Navarro Xavier Cabral. Capítulo 1. È urgente construir alternativas á justiça. Salvador:Juspodivm, 2016

PINHO, Humberto Dalla Bernardina de; PAUGGARTTEN; Michele Pedrosa. Os desafios para a integração entre o sistema jurisdicional e a mediação a partir do Novo Código de Processo Civil: quais as perspectivas para a justiça brasileira? In: ALMEIDA, Diogo Assumpção Rezende;

PANTOJA, Fernanda Medina; PELAJO, Samantha (Coord.). A mediação no novo código de processo civil. 2. ed. Rio de Janeiro: Forense, 2016.

PIZZOTTI, Maria Lúcia. Conciliação e mediação: da necessidade de adequada capacitação para obtenção de resultados efetivos. In: SILVA, João José Custódio da; AMORIM, José Roberto Neves (Coord.). A Nova Ordem das Soluções Alternativas 
de Conflitos e o Conselho Nacional de Justiça. São Paulo: Gazeta Jurídica, 2013. RODRIGUES JÚNIOR, Walsir Edson. A prática da mediação eu acesso à justiça. Belo Horizonte: Del Rey, 2006.

SILVEIRA, João José Custódio da. Desafios à Nova Ordem de Soluções Diferenciadas para Acesso à Justiça. In: SILVEIRA, João José Custódio da; AMORIM, José Roberto Neves (Coord.). A Nova Ordem das Soluções Alternativas de Conflitos e o Conselho Nacional de Justiça. Brasília: Gazeta Jurídica, 2013.

WATANABE, Kazuo apud MINGATI, Vinícius Secafen; RICCI, Milena Mara da Silva. Conceito de acesso à justiça: a efetividade do processo como garantia de acesso à uma ordem jurídica justa. Disponível em: <http://eventos.uenp.edu.br/sid/publicacao/artigos/1.pdf>. Acesso em: 23 jan. 2017.

Sites:

BRASIL. Lei n. 13.105, de 16 de março de 2015. Código de Processo Civil. Disponível em: <http://www.planalto.gov.br/ccivil_03/_ato2015-2018/2015/lei/113105. htm>. Acesso em: 24 maio. 2017.

BRASIL. Constituição da República Federativa do Brasil de 1988. Disponível em: <http://www.planalto.gov.br/ccivil_03/constituicao/constituicaocompilado. htm>. Acesso em: 25 de maio. 2017.

BRASIL. Conselho Nacional de Justiça. Resolução n. 125 de 29 de novembro de 2010. Dispõe sobre a Política Judiciária Nacional de tratamento adequado dos conflitos de interesses no âmbito do Poder Judiciário e dá outras providências. Disponível em: <http:/ / www.cnj.jus.br/busca-atos-adm?documento=2579>. Acesso em: 28 abr. 2017. 